\title{
Activating Student Voice in Social Change
}

\author{
Natasha DiGenova, OCT
}

The Woodlands Secondary School

\section{"It is not enough to be compassionate. You must act."}

\section{-The Dalai Lama}

This quote summarizes my experience with carrying out research-informed and negotiated action (RiNA) projects with my science classes over the past 2 years. I am a long-term occasional (LTO) teacher with the Peel District School Board (PDSB). In midSeptember of 2017, I was fortunate to accept a science LTO position at Cawthra Park Secondary School (CPSS) in Mississauga, Ontario. Being my very first full-year teaching role, I was extremely overwhelmed to say the least. I was given 3 completely different courses to teach, but I was eager and excited to get started.

The science department quickly introduced RiNA to me, as Mirjan Krstovic, the Instructional Coach at the time, was already having meetings with the other science teachers. They invited me to join their RiNA team. I was already so overwhelmed with preparing for my first ever classes, so I figured that I may as well take a leap! And I am so glad I did! Mirjan Krstovic along with the teachers at CPSS made me feel comfortable to engage with this project, as it was their first time carrying out RiNA as well. It was a learning experience for all!

As I reflect on the very first round of RiNA (Fall 2017), a lot has changed since introducing it to current classes. But one aspect that has remained the same, is the success I have had motivating and engaging my students to be activists of social change, which was the ultimate goal!

In September 2018 I started a new LTO position at The Woodlands School in Mississauga, Ontario. I had a Grade 9 Enhanced Science class first semester and was excited to introduce RiNA to them! I also made an attempt at sharing the project with my colleagues. I have to admit, it was not well received at first. After some convincing and time spent explaining the process, I had multiple teachers on board. The great thing about introducing RiNA to a large group of educators, was putting our ideas together on how we could improve the process. Every teacher made RiNA their own.

The empathy, enthusiasm and passion my students have shown for Science, Technology, Society and the Environment (STSE) issues addressed over the past 2 years completing RiNA projects brought me joy and pride. More so, my students' willingness to make social change and act on these issues gives me hope that our world will be well taken care of by today's youth; tomorrow's future! 